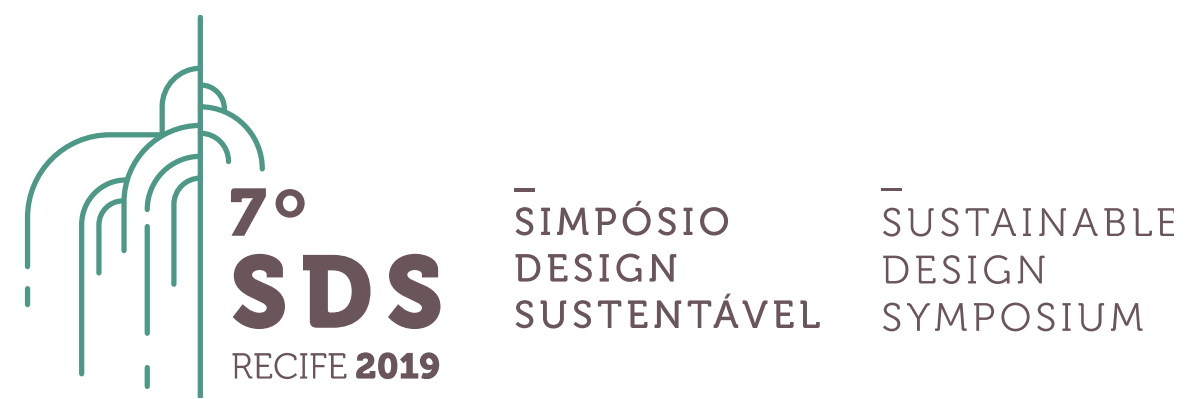

\title{
The importance of introduction the artisanal technique in the Textile and Clothing Chain in Recife- PE
}

\author{
Lara Brito Leite ${ }^{1, a}$, Maria Alice Vasconcelos Rocha ${ }^{2}$ \\ ${ }^{1}$ UFRPE, Ciências Sociais, laramirra@outlook.com \\ ${ }^{2}$ UFRPE, Ciências Domésticas, modalice@gmail.com
}

\begin{abstract}
The activities of textile production have been in the State of Pernambuco since the second half of the 19th century with the foundation of the Fabric Factory of Madalena, located in the city of Recife. However, the production of textiles in the state does not have a linear trajectory and has always been surrounded by the most different confrontations, so it was not until the end of the 20th century that the Textile and Clothing Chain ( $T$ \& $C$ ) received incentives from the state governments, allowing their valorization and growth. There are many challenges facing the industry today, among which we must highlight the concern of some brands in dialoguing with the current sustainable paradigm while proposing to propagate the local culture, using in their production a workforce inclined especially for the craft processes. The present study aims to discuss the importance of artisanal practice within the T\& C-PE Chain, adding productive value to local aesthetics and promoting an effectively fair economy.
\end{abstract}

Keywords. Artisanal, aesthetic, fashion, Textile, Pernambuco.

\section{Introdução}

A Cadeia Têxtil e de Confecções em Pernambuco ocupa atualmente uma posição de destaque no território nacional. Segundo dados do IEMI ${ }^{\mathrm{a}}$ (2017), Pernambuco é o sétimo Estado do Brasil na escala de produtores de têxteis, tendo no ano de 2016 uma produção de 46 mil toneladas de têxteis básicos com valor de produção de 1 bilhão de Reais nesse mesmo ano. Este é o reflexo de uma longa trajetória que teve início no ano de 1876 na cidade do Recife, com a Fábrica da Madalena que continha 45 teares mecânicos de ferro e mestres tecelões trazidos de outros países. Em seguida foram instaladas a Companhia de Fiação e Tecidos de Pernambuco (Fábrica da Torre), Fábrica de Tecidos Paulista (1891) e a Cia. Industrial Pernambucana no munícipio de Camaragibe (1891). Posteriormente, pode-se destacar a Fiação de Tecidos e Malha que ficava próxima do Recife e confeccionava meias para todo o país, em 1898 era considerada "uma fábrica arrojada para época, com seção de tinturaria e branqueamento impecáveis, equipada com hidroextractores e estufas." (Braga; Prado, 2011, p.42).

\footnotetext{
${ }^{a}$ Dados disponíveis em relatório no site do IEMI- Inteligência de Mercado Ltda (www.iemi.com.br). 
Após o período do Brasil-Colônia, podemos destacar, na atividade varejista a fundação das Casas Pernambucanas em 1908. Para João Braga (2013), as Casas Pernambucanas ajudaram de maneira ímpar o desenvolver do setor algodoeiro no Brasil, assim como a produção têxtil e também a comercialização de linhas, máquinas de costura e aviamentos, permanecendo, ainda na atualidade entre uma das maiores varejistas do país. Entretanto, a partir do ano de 1930 a produção de têxteis no Brasil acaba por migrar para o Sul e Sudeste, o resultado disso é a ruína do pólo de confecções do Nordeste, que só consegue se reerguer cinquenta anos depois. De acordo com os dados fornecidos pelo Banco do Nordeste do Brasil, Viana (2005) afirma que apenas nas décadas de 1980 e 1990 no século XX, após incentivos fiscais dos governos estaduais, é que o setor têxtil e de confecções pernambucano veio a se recuperar do abalo de outrora.

A Cadeia T\&C-PE é composta atualmente pelos pólos do Agreste, composto pelas cidades de Toritama, Caruaru e Santa Cruz do Capibaribe e seus arredores, e o pólo da Região Metropolitana do Recife. Faz-se importante entender que as práticas de uma economia justa permeiam o debate acerca da produção vestimentar no Estado, indo para além das temáticas já vigentes, como a questão da lavagem do jeans em Toritama ou a questão do emprego informal em Santa Cruz. Por isso, o presente estudo tem como objetivo discorrer sobre os aspectos atuais que compõem a Cadeia T\&C-PE, levando em consideração a apreensão de novos paradigmas traduzidos dentro da produção e também da estética vestimentar. Dentre eles, podemos destacar a prática do processo artesanal por alguns produtores inseridos na cadeia que, de acordo com Favilla, Barreto e Rezende (2016, p.11) pode ser definido como "[...] uma espécie de contrapartida à massificação e à uniformização de produtos, promovendo o resgate cultural e a identidade regional".

Seguindo essas diretrizes, este estudo busca refletir sobre as práticas artesanais alternativas dentro da produção do pólo do Recife, em especial, dentre as marcas que ficaram incubadas no Marco Pernambucano da Moda durante os anos de 2017-2018. Este resultado faz parte de uma pesquisa maior realizada pela Universidade Federal Rural de Pernambuco e do CNPq, através do Programa de Iniciação Científica da mesma universidade e do projeto de pesquisa intitulado "Aspectos estéticos relevantes na cadeia têxtil e de confecções em Pernambuco" realizado durante o período de Agosto de 2018 a Março de 2019.

\section{A Cadeia T\&C- PE: o contexto histórico de sua trajetória}

Ao contar essa história por meio da ordem cronológica, deve-se primeiro tratar das cidades do Agreste pernambucano, para em um segundo momento levar em consideração a cidade do Recife. Sabe-se que a cidade de Santa Cruz do Capibaribe foi a primeira a se inclinar ao comércio e produção de têxteis, assim como nos informa Pereira Neto (2013), entre os anos de 1950 até 1960 um novo meio de subsistência surgiu no local: a produção semiartesanal de roupas, tendo como intuito inicial suprir a carência de empregos e fornecer uma renda para além das atividades rurais.

A Feira da Sulanca foi o espaço escolhido para comercialização de insumos, inicialmente, a dinâmica era composta pela compra e venda de retalhos e de pedaços de helanca, tendo uma produção focada em peças simples como colchas de retalhos, bermudas e camisas com preço e qualidade abaixo do mercado formal (PEREIRA NETO, 2013). Essas peças eram destinadas a um público de baixo poder econômico, por isso, os preços populares eram os grandes atrativos. $\mathrm{Na}$ medida em que tal atividade foi se estabelecendo, uma nova clientela surgiu e novos produtores e vendedores foram incorporados (OLIVEIRA, 2012). No ano de 1970, no entanto, a Feira da Sulanca não era mais voltada à produção semiartesanal e as peças produzidas e comercializadas no local já haviam passado pelo processo de industrialização. Tal empreendimento foi ganhando espaço, e em 1990 a feira dedicava-se apenas à venda de confecções e ocupava 28 ruas do centro da cidade de Santa Cruz do Capibaribe, empregando milhares de trabalhadores formais e informais. 
Segundo estudos realizados pela Universidade Federal de Pernambuco e o Sebrae, no ano de 2003 não havia desemprego no local, muito pelo contrário, a mão de obra especializada na costura sempre foi procurada, mesmo ressaltando que boa parte da produção era realizada de maneira informal e muitas vezes com mão de obra familiar. Muitos costureiros e costureiras aprenderam o ofício observado desde a infância, e, mesmo assim, a produção do polo no período chegava a 35 milhões de peças mensais (FADE-UFPE/SEBRAE, 2003). Deve-se, com esses dados em mãos, entender a relativa rapidez no que tange à grandiosidade da produção desse pólo de confecções que, em menos de 40 anos, fez a pequena cidade de Santa Cruz do Capibaribe sair de uma economia de subsistência agrária para uma de confecção e manufatura têxtil. Mesmo com diversos obstáculos no quesito formal de sua produção, obteve rápida industrialização atingindo números grandiosos e ajudando a colocar o Estado de Pernambuco na rota têxtil do país.

\subsection{A Cadeia T\&C-PE, a história do Pólo do Agreste: Toritama \& Caruaru}

Com o sucesso da produção têxtil e de confecções de Santa Cruz do Capibaribe (Sta Cruz do Cap), as cidades vizinhas do interior do Estado de Pernambuco começaram a se inspirar e migrar suas atividades do setor agrário para a confecção de produtos vestimentares. A cidade de Toritama se encontra à $21 \mathrm{~km}$ de Sta Cruz do Cap, sendo que no local já havia, desde 1930, a confecção artesanal de sapatos como nos afirma Pereira Neto (2013). Entretanto, com o surgimento das grandes indústrias de calçados estabelecidas no sul do Brasil, a produção artesanal do Agreste foi decaindo, e assim, Toritama se viu obrigada a encontrar novos caminhos para subsistência. Seguiu então para o ramo das costuras dos tecidos mais pesados como o jeans, tendo como ponto forte o maquinário que anteriormente era usado na produção de calçados.

Logo, a cidade focou suas atividades na produção do jeans, sendo esse seu principal e praticamente único produto final, por isso, a cidade ficou conhecida como "A Capital do Jeans" (Araújo, 2006). O jeans representa $66 \%$ de sua produção total, fazendo com que $15 \%$ da produção nacional provenha do município (SILVA, 2009, p.13). O crescimento de Toritama foi tão rápido que no ano de 2013 ela era a segunda maior cidade do Brasil especializada na fabricação de roupas jeans, ficando atrás somente do pólo do Brás em São Paulo. Pereira Neto (2013) afirma que a cidade produz 2 milhões de peças por mês, recebe em média 10 mil compradores por semana e possui mais de 2 mil fabricos e facções. Sem dúvidas, os números são bastante expressivos e nos ajudam a compreender como a produção vestimentar sustenta os mais de 40 mil habitantes do local.

Caruaru sempre foi uma rota para comerciantes que passavam pelo interior do Estado de Pernambuco, suas feiras livres, seu artesanato e produções locais deram-lhe o título de "Capital do Agreste", tendo como principal atrativo a Feira de Caruaru, que atualmente tem mais de 200 anos. Pereira Neto (2013) coloca em evidência que, comparada às outras cidades do seu entorno, a economia de Caruaru é a mais diversificada, por isso, a cidade possui diversas empresas de micro, pequeno e médio porte. Foi nos anos de 1970 que, ao estreitar laços comerciais com Santa Cruz e Toritama, a cidade passou a também investir na confecção e comercialização de roupas, surgindo a Feira da Sulanca, localizada no parque 18 de Maio. Estima-se que, em média, 45 mil pessoas visitam semanalmente as grandes feiras de confecções populares realizadas nas três principais cidades do pólo: Caruaru, Santa Cruz do Capibaribe e Toritama (FADE/UFPE, 2003).

\subsection{A Cadeia T\&C de Pernambuco: A Região Metropolitana \& o Marco da Moda}

Dentre as cidades da Região Metropolitana do Recife pode-se destacar a capital do Estado de Pernambuco, Recife, como a maior no quesito de abrigar as marcas de maior expressão no que tange o valor simbólico. Também é em Recife que se encontra uma das duas sedes do Núcleo Gestor da Cadeia Têxtil e de Confecções de Pernambuco- NTCPE, juntamente com o espaço criativo Marco Pernambucano de Moda, ambos localizados no centro histórico da cidade. De 
acordo com o site do Núcleo Gestor da Cadeia Têxtil e de Confecções de Pernambuco (NTCPE) ${ }^{b}$, esse é uma organização social privada, fundada no ano de 2012 por empresários da Sindivest, Sinditêxtil e a Federação das Associações Comerciais de Pernambuco. O objetivo da organização é promover a inovação, a cooperação e o intercâmbio entre as empresas do segmento, o setor público e a academia, contando com o apoio do Governo do Estado de Pernambuco. O Marco Pernambucano da Moda é uma das iniciativas promovidas pelo NTCPE, e teve sua criação no ano de 2014 com o intuito de disponibilizar serviços para profissionais e empresários da Cadeia T\&C$\mathrm{PE}$, promovendo, também, eventos abertos ao público em geral (Disponível em: www.ntcpe.org.br).

De acordo com Rocha, Barrocas e Marinho (2018) foi no ano de 2013 que o NTCPE assinou seu primeiro contrato de gestão, com inicialmente quatro metas a serem realizadas: 1) Estruturar - Marco Pernambucano da Moda na Rua da Moeda; 2) Ser referência em inteligência mercadológica; 3) Ampliar o acesso da cadeia pernambucana ao mercado nacional e 4) implantar o programa de capacitação e incubação no Marco da Moda. Em 2015, um desfile realizado no local apresentou à sociedade as coleções da primeira classe de incubados. Em 2017, o governo de Pernambuco tornou público uma apostila sobre Estratégia de Ciência, Tecnologia e Inovação para Pernambuco 2017-2022 (ECT\&I-PE). Dentre as muitas preocupações desse estudo, uma que podemos destacar foi a construção de um Sistema Pernambucano de Inovação (SPIn) onde o Marco Pernambucano da Moda e o NTCPE foram classificados como organizações "ponte" para a interação e promoção de inovação das empresas (ALMEIDA FERNANDES; PINTO DE MELO, 2017).

De acordo com as autoras supracitadas (2017), essas organizações do tipo "ponte" atuam na articulação entre as competências acadêmicas (Universidades, Fundações de Apoio, etc.) e o chamado setor produtivo. Incentivados por políticas públicas visionárias, acabam por estruturar habitats de inovação em Pernambuco. Sendo assim, pode-se perceber que existe uma grande diferença entre as funções que são atribuídas aos dois polos da Cadeia T\&C em Pernambuco, evidenciado na fala de um designer do Recife na obra "Interlaçados" produzida pelas pesquisadoras Rocha, Barrocas e Marinho (2018, p.74): “Porque o Agreste produz, lá eles têm escala de produção. Aqui a gente tem criação, é onde estão os designers, onde estão as pessoas que pensam a moda. E lá é produção, é maquinário, é mão de obra, então, se a gente conseguir fazer essa junção, a gente entender isso como cadeia de valor...ninguém nos segura".

\section{O Programa do Artesanato Brasileiro e o Estado de Pernambuco}

No ano de 2010, o governo do Brasil por meio do Decreto de Lei n. 7.096 tornou público a base conceitual do artesanato no país, esse documento permitiu padronizar e estabelecer os parâmetros de atuação do Programa do Artesanato Brasileiro - PAB em todo o território nacional, trazendo à luz a compreensão conceitual do que se trata a prática artesanal, tendo como fim principal a criação de políticas públicas e a contribuição com o planejamento de ações de fomento para o setor. De acordo com o documento o artesanato é:

Art. 4ㅇ ARTESANATO - Artesanato compreende toda a produção resultante da transformação de matérias-primas, com predominância manual, por indivíduo que detenha o domínio integral de uma ou mais técnicas, aliando criatividade, habilidade e valor cultural (possui valor simbólico e identidade cultural), podendo no processo de sua atividade ocorrer o auxílio limitado de máquinas, ferramentas, artefatos e utensílios (PAB, 2010, p.3).

Dessa forma entende-se que a produção artesanal acontece por meio da transformação manual de matérias primas, de modo que seja agregado valor simbólico e cultural. Para isso, são utilizadas as mais diversas técnicas e materiais, esses estão citados ao longo do programa:

\footnotetext{
${ }^{\mathrm{b}}$ Informação disponível no site: www.ntcpe.org.br
} 
cerâmica, chifre, areias coloridas, conchas, couros, fibras, metais, papéis, madeiras, etc. (PAB, 2010). Os fios e tecidos aparecem com destaque no VIII parágrafo da página 08 devido a sua especificidade, já que são produzidos a partir de fibras têxteis e por meio desses são confeccionados infinitos materiais:

"VIII - FIOS E TECIDOS - Apesar dos fios e tecidos serem produzidos a partir de fibras têxteis, constituirão uma tipologia específica devido à diversidade de produtos confeccionados e técnicas que os utilizam como material básico" (PAB, 2010, p.8).

Entende-se que os fios e os tecidos podem ser confeccionados com fibras naturais, vegetais e de origem animal. As naturais são frutos da natureza e não sofrem transformações químicas; as de origem animal são as sedas, lã, peles, etc., e, de origem vegetal são os linhos, algodão, rami, sisal, coco e outros. De acordo com dados do $\mathrm{IBGE}^{\mathrm{C}}$ apud Favilla, Barreto e Rezende (2016), 67\% dos municípios no país têm o artesanato presente na economia. Em Pernambuco o artesanato atua de maneira extremamente resistente, permitindo manter viva a memória da estética popular local. Para o ex-governador do Estado, Eduardo Campos, a atividade é capaz de "traduzir artisticamente a alma pernambucana e preservar nossa cultura, é, também, setor da economia com grande potencial de geração de emprego e renda" (SEBRAE, 2013, p.5).

De acordo com o Site do artesanato em Pernambuco ${ }^{d}$, algumas são as ações no Estado para venda e propagação das peças produzidas no local, dentre elas, a criação do Programa do Artesanato de Pernambuco (PAPE), em 2008, pela Agência de Desenvolvimento Econômico de Pernambuco (AD Diper), a criação da Feira Nacional de Negócios do Artesanato (Fenearte), que atualmente é considerada a maior feira de artesanato da América Latina, os dois Centros de Artesanato de Pernambuco (Recife e Bezerros) e a Unidade Móvel do Artesanato, in (http://www.artesanatodepernambuco.pe.gov.br). Tais ações são notáveis na realidade social pernambucana, sendo atração para moradores locais e turistas. Sendo assim, é de importância para o setor têxtil dialogar com o artesanato, tendo como fim a dinamicidade da economia local.

\title{
3.1.1 O artesanato como vetor para inovação da CT\&C-PE
}

De acordo com o dados fornecidos pelo IEMI-Inteligência de Mercado Ltda (2017) um dos grandes desafios para expansão da produção têxtil local em âmbito nacional e internacional é a construção de uma identidade estética própria:

\begin{abstract}
A proposição é criar peças de vestuário e de cama, mesa e banho de médio e alto valores agregados, que traduzam a arte e a cultura pernambucanas em grande estilo, com cores, estampas e modelagens relacionadas ao modo de vida de sua população, sem perder de vista as tendências internacionais da moda e os desejos dos consumidores-alvo, em grande parte formados por "não pernambucanos" (IEMI, 2017, p. 132).
\end{abstract}

No site oficial do Marco Pernambucano da Moda (www.marcopemoda.com.br) consta que no ano de 2017 o programa de incubação selecionou 09 marcas de pequenos produtores regionais, são essas: Calle, Concha Carioca, Cobogó, Dona Quitéria, Lala Di, Menina dos Olhos, Peamo, Rafa Que Faz e Soy Marina. Cada uma delas traz consigo uma identidade própria, suas visões de mundo e ideais, entretanto, pôde-se observar que algumas tinham objetivos voltados à prática artesã, levando em consideração em suas produções o reaproveitamento de insumos e a valorização da estética local, tais dados foram obtidos através de pesquisa online nas plataformas digitais de cada marca e após isso, utilizou-se a metodologia da análise iconográfica. Dentre as nove marcas, utilizaremos como referencial as seguintes, tendo e vista contemplar a temática aqui abordada: Cobogó, Menina dos Olhos, Rafa Que Faz, Soy Marina e Dona Quitéria.

A Cobogó é descrita no site do Marco da Moda como voltada para o público feminino, para

\footnotetext{
${ }^{\mathrm{c}}$ Instituto Brasileiro de Geografa e Estatística.

${ }^{\mathrm{d}} \mathrm{http}: / / \mathrm{www}$.artesanatodepernambuco.pe.gov.br
} 
aquelas que valorizam quem faz com as próprias mãos, dessa forma, a marca investe em matérias primas nacionais, visando um modo de vida sustentável. A marca é pensada por Heloísa Sena e Mariana Siqueira. Abaixo (Figuras 1 e 2) pode-se visualizar algumas de suas peças, assim como a produção artesanal das mesmas, onde todo o processo de confecção da blusa é manual.

Figura 1 - Coleção Retrô Cobogó

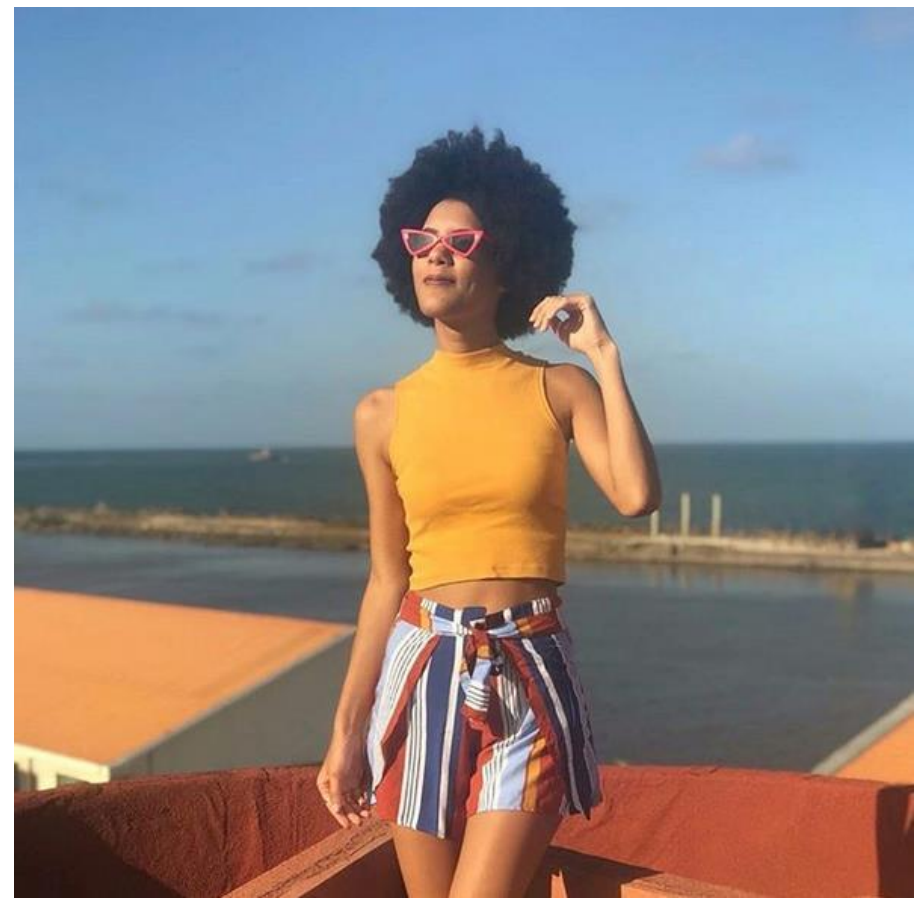

Fonte: https://www.instagram.com/usecobogo/ (2019)

Figura 2 - Estamparia artesanal Cobogó

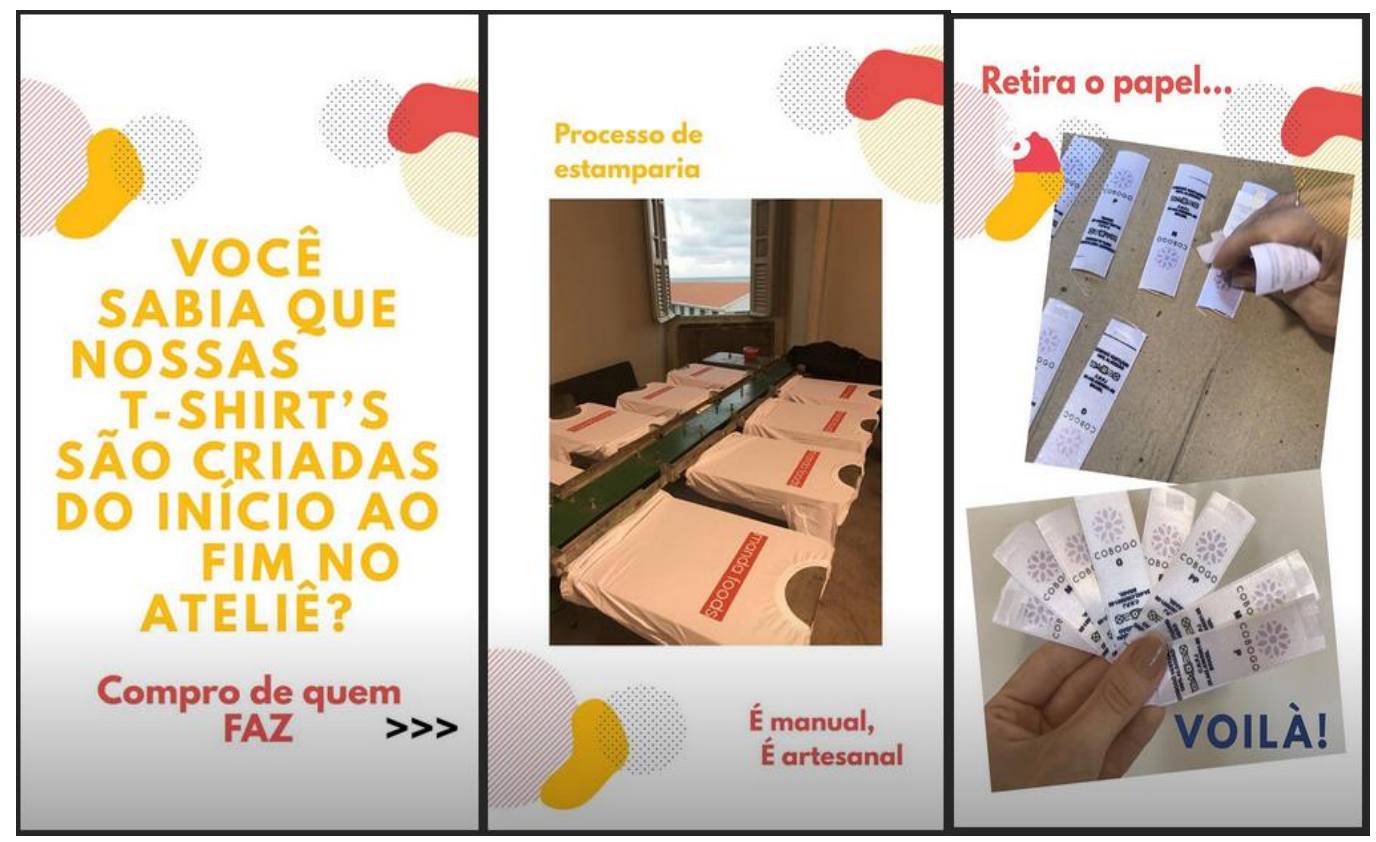

Fonte: https://www.instagram.com/usecobogo/ (2019)

A Dona Quitéria é uma marca de moda casual com um toque artesanal, e tem nome e estética que lembram o carinho de avó. Suas peças são produzidas em especial com fibras naturais, que são mais duráveis e têm menor impacto ambiental (Figura 3). 
Figura 3 - Processo de produção de saia

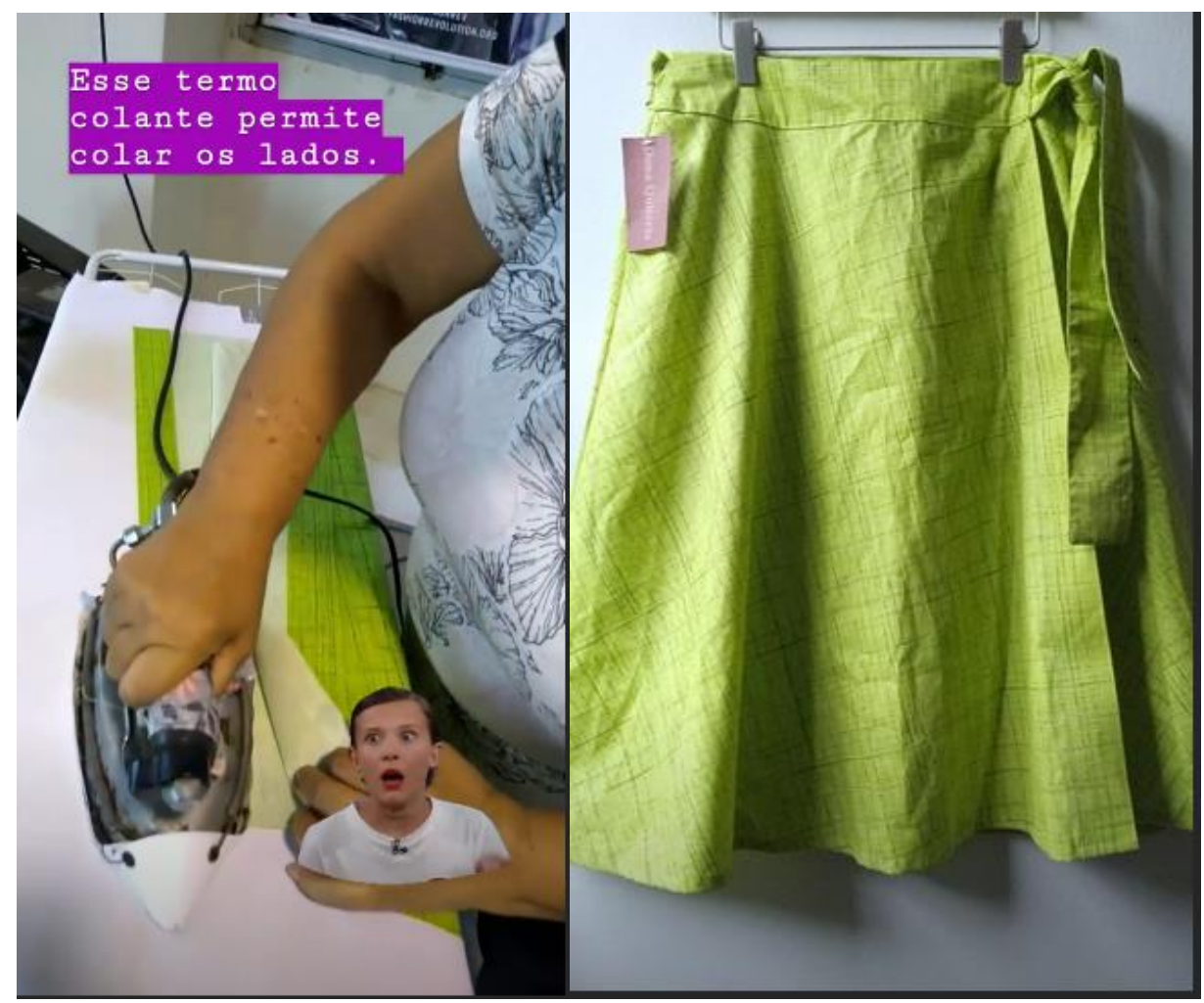

Fonte: https://www.instagram.com/quiteriadona/ (2019)

Carol Frexeira e Helena Leal estão à frente da marca Menina dos Olhos, o seu conceito inclui uma moda pautada no slow fashion, termo que remete à prática de consumo e produção de uma roupa mais duradoura (Figura 4) indo contra o consumo rápido de roupas, conhecido como fast fashion.

Figura 4 - Vestidos da marca Menina dos Olhos
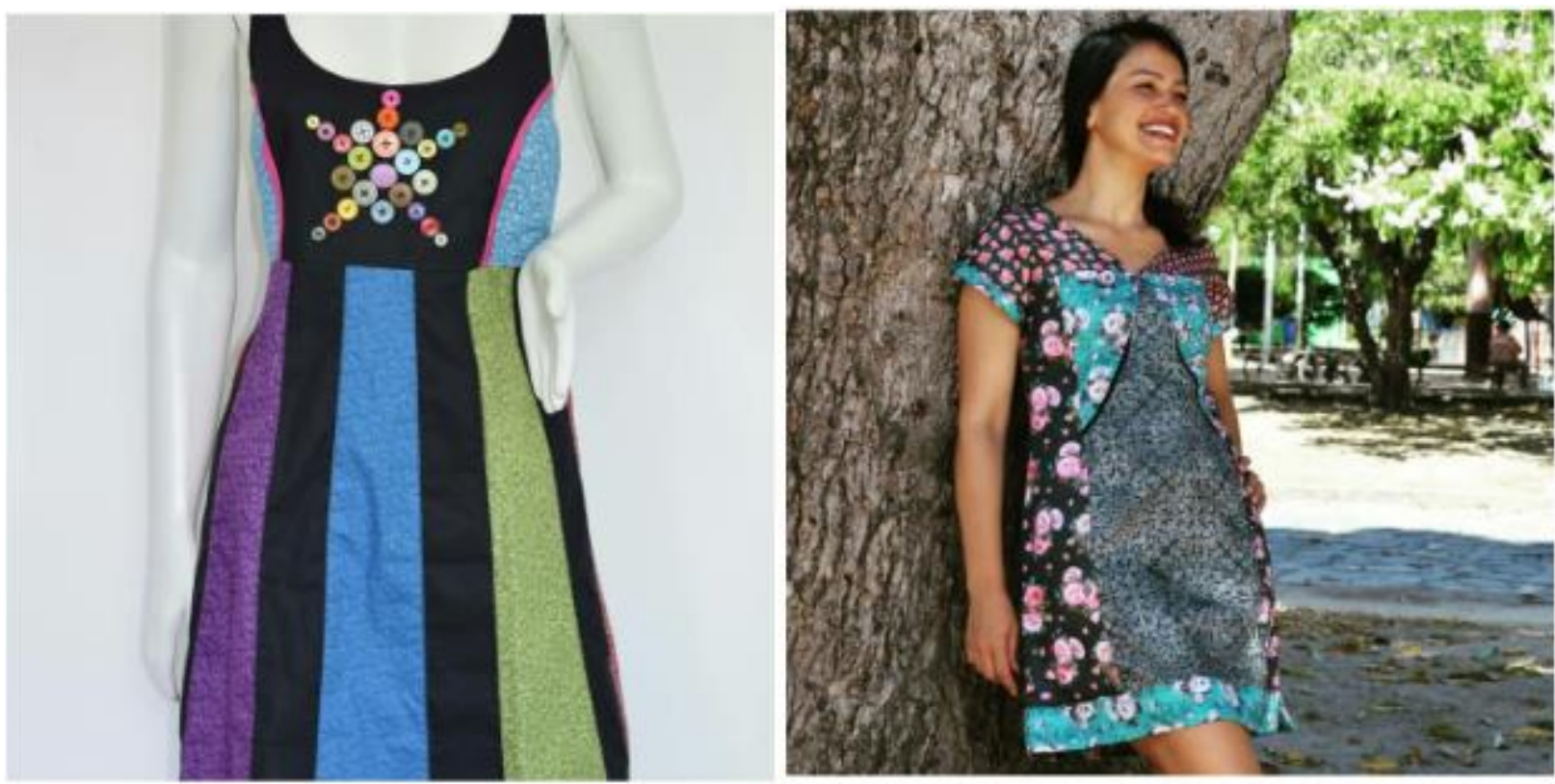

Fonte: https://www.instagram.com/meninadosolhos.loja/ (2019)

A Rafa Que Faz, possui uma identidade local muito forte em suas peças, inspirada nas 
belezas da cidade histórica de Olinda, visto que a marca desenvolve estampas coloridas e que leva para o consumidor cores vibrantes e jovialidade (Figuras 5 e 6).

Figura 5 - Estampa do folclore local e de Peixinhos em Olinda.

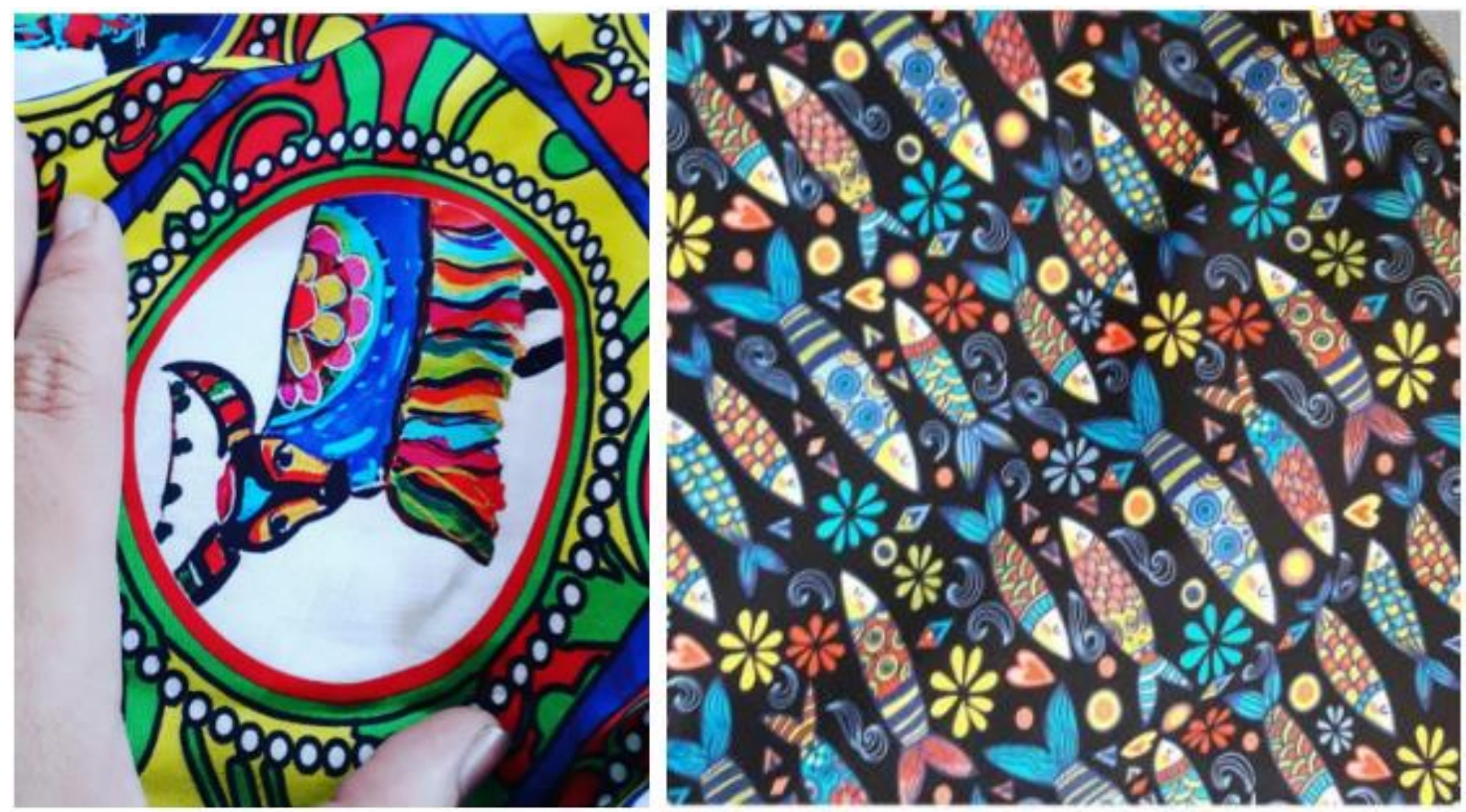

Fonte: https://www.instagram.com/rafaqfaz/ (2019)

Figura 6 - Estampas e desfile da marca.



Fonte: https://www.instagram.com/rafaqfaz/ (2019)

A marca Soy Marina é a única que atua voltada especificamente para a produção de acessórios, sendo idealizada por Marina Pordeus que confecciona peças exclusivas e as comercializa através da internet para todo o Brasil (Figura 7). 
Figura 7- Anéis da marca Soy Marina
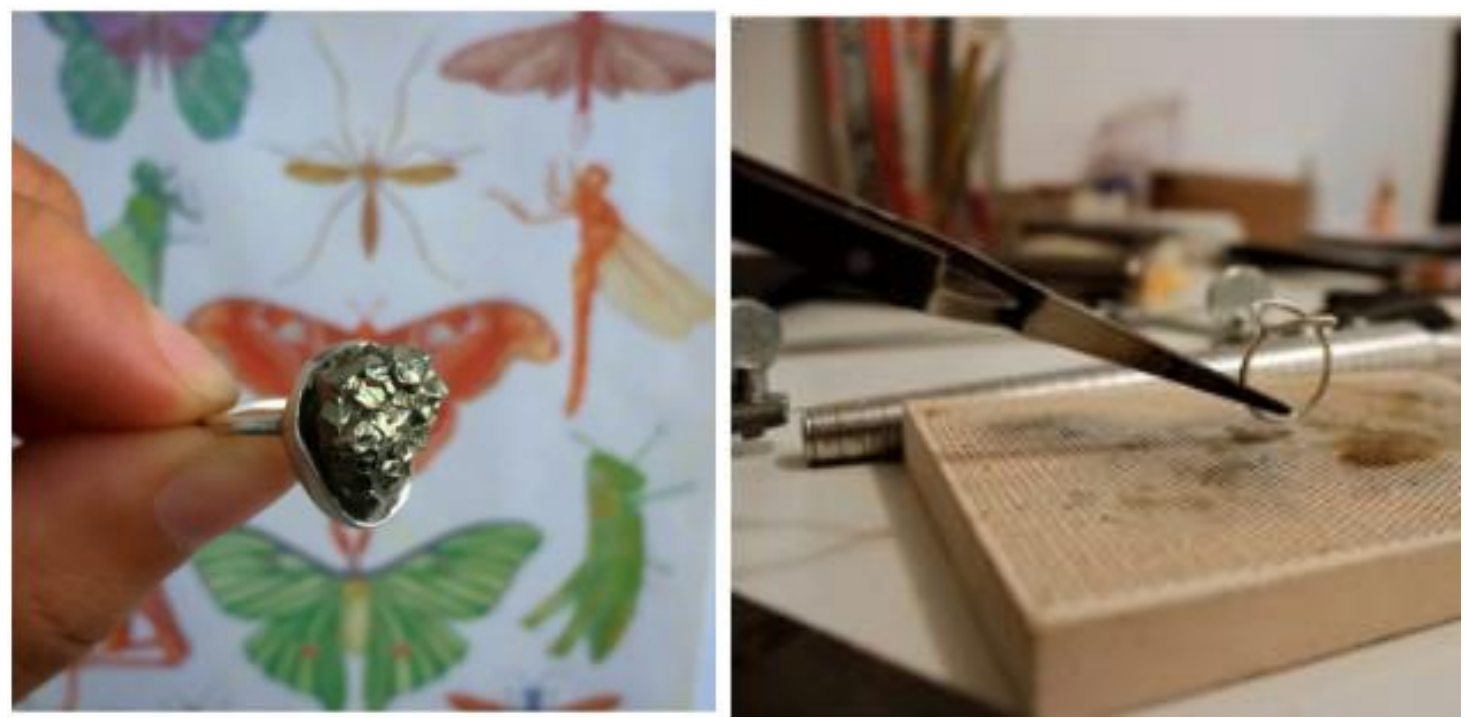

Fonte: https://www.instagram.com/soy_marina/ (2019)

\subsubsection{Considerações Finais}

No presente estudo buscou-se através de pesquisa documental e revisão bibliográfica construir uma linha do tempo no que tange a criação da Cadeia Têxtil e de Confecções de Pernambuco, tendo como enfoque principal apresentar algumas das marcas do setor que na atualidade trabalham visando uma moda mais sustentável, mais duradoura e inspirada na estética local utilizando da técnica artesanal em suas confecções. Algumas marcas incubadas no Marco Pernambucano da Moda no ano de 2017 foram utilizadas como referência, já que usam técnicas artesanais na construção de suas peças, de modo à integrar instrumentos com atividades manuais, são elas: Cobogó, Menina dos Olhos, Rafa Que Faz, Soy Marina e Dona Quitéria.

Pôde-se perceber que o artesanato é de fato uma via alternativa para construção de moda, mesmo para aqueles como os citados acima que estão inseridos dentro de uma lógica de produção têxtil. Deve-se chamar atenção que dentre os incubados no programa do Marco da Moda entre 2017 e 2018, mais da metade possuem como identidade da marca a prática artesanal dos produtos. Esse resultado corrobora com as indicações do IEMI para expansão em nível nacional dos têxteis locais, no que tange a construção de "peças de vestuário e de cama, mesa e banho de médio e alto valores agregados, que traduzam a arte e a cultura pernambucanas em grande estilo, com cores, estampas e modelagens relacionadas ao modo de vida de sua população" (IEMI, 2017, p. 132). Ainda, sabe-se que muitos são os artesãos do Estado de Pernambuco e que de certa forma os tecidos compõem suas mais distintas artes, dando ampla possibilidade para novos estudos e construções acadêmicas acerca da temática.

Espera-se com este artigo contribuir na caminhada de construção de um novo paradigma social que, para além de valorizar o artesanato local em peças para decoração, valorize-o nas roupas e criações do setor têxtil em geral, já que esta prática acaba por permear nos entreames de uma economia mais justa. Também, espera-se contribuir para futuros estudos sobre a Cadeia Têxtil e de Confecções de Pernambuco, assim como sobre o pólo de moda do Recife e o Marco Pernambucano da Moda.

\section{Referências}

ARAÚJO, Carlos Augusto Lucena. Análise da Cadeia Têxtil e de Confecções do Estado de Pernambuco e os impactos nela decorrentes do fim do acordo sobre têxteis e vestuário-ATV. 
2006. Dissertação (Mestrado em Comércio Exterior e Relações Internacionais) - Universidade Federal de Pernambuco, Recife, 2006.

BRAGA, João. Um século de moda. São Paulo: D'livros editora, 2013.

FADE / UFPE. Estudo de Caracterização Econômica do Pólo de Confecções do Agreste Pernambucano. FADE/UFPE/SEBRAE: Recife, 2003.

FAVILLA, Clara; BARRETO, Luciana; REZENDE, Renata. Artesanato Brasil. Brasília: Sebrae, 2016.

FERNANDES, Ana Cristina de Almeida; MELO, Lucia Carvalho Pinto de. Estratégia de ciência, tecnologia e inovação para Pernambuco 2017 - 2022: uma política localmente inspirada, globalmente. Recife: Secretaria de Ciência, Tecnologia e Inovação do Estado de Pernambuco, 2017.

IEMI. Estudo da Competitividade dos Setores Têxtil e Confeccionista no Estado de Pernambuco. Disponível em: <www.iemi.com.br> Acesso em: 02 de novembro de 2018.

OLIVEIRA, Roberto Véras de. 0 pólo de confecções do agreste de Pernambuco: ensaiando uma perspectiva de abordagem Popular. 35 Encontro Anual da ANPOCS, Minas Gerais, 2012.

PAB. Portaria № 29, De 05 De Outubro De 2010. Disponível em: <http://www.secretariadegoverno.gov.br/micro-e-pequena-empresa/assuntos/programa-doartesanato-brasileiro> Acesso em: 30 de Março de 2019.

PEREIRA NETO, Eugenio Vital. Qualificação e informalidade: os modos de atuação do Senai no Polo de Confecções de Pernambuco. Recife: Fundação Joaquim Nabuco, 2013.

PRADO, Luís; BRAGA, João. História da moda no Brasil: das influências às autorreferências. São Paulo: Disal, 2011.

ROCHA, Maria Alice; BARROCAS, Luiza; MARINHO, Nathilucy. Interlaçados: trajetórias da Cadeia Têxtil e de Confecções em Pernambuco narradas pela cultura do consumo. Recife: FUNCULTURA/Governo do Estado de Pernambuco, 2018.

SEBRAE. Artesanato de Pernambuco. Recife: SEBRAE/PE, 2013.

SILVA, Sandra Roberta. A juventude na "Sulanca": os desafios da inserção do mundo em Taquaritinga do Norte/PE. 2009. Dissertação (Mestrado em Ciências Sociais) - Universidade Federal de Campina Grande, Campina Grande, 2009.

VIANA, Fernando. A indústria têxtil e de confecções no Nordeste: características, desafios e oportunidades. Fortaleza: Banco do Nordeste do Brasil, 2005. 